\title{
From demand response to integrated demand response: review and prospect of research and application
}

\author{
Wujing Huang ${ }^{1}$, Ning Zhang ${ }^{1 *}$ (D, Chongqing Kang ${ }^{1}$, Mingxuan $\mathrm{Li}^{1}$ and Molin $\mathrm{HuO}^{2}$
}

\begin{abstract}
In the traditional power system demand response, customers respond to electricity price or incentive and change their original power consumption pattern accordingly to gain additional benefits. With the development of multienergy systems (MES) in which electricity, heat, natural gas and other forms of energy are coupled with each other, all types of energy customers are able to participate in demand response, leading to the concept of integrated demand response (IDR). In IDR, energy consumers can response not only by reducing energy consumption or opting for off-peak energy consumption but also by changing the type of the consumed energy. Taking the traditional demand response in power system as a starting point, the studies of the fundamental theory, framework design and potential estimation of demand response in power system are reviewed, and the practical cases and software development of demand response are introduced. Finally, the current theoretical research and application of IDR are assessed.
\end{abstract}

Keywords: Demand response, Integrated demand response, Multi-energy systems, Integrated energy systems, Energy hub, Energy storage, Microgrid, Renewable energy, Gas network, Clustering analysis, Review

\section{Introduction}

With the deep transformation of the national energy structure, the ability of resource allocation of the traditional energy network is gradually unable to meet the development needs of future energy systems. The technology and market environment for implementing demand response have significantly changed, and the optimal coordination of the supply and demand in the Energy Internet cannot be effectively realized only by considering the demand response in power system. Instead, an integrated demand response (IDR) is required whose technical requirements cannot be met only by considering power system scheduling and control. Furthermore, the existing market framework and incentive mechanism cannot be adapted to a more complex market structure for the multi-energy systems (MES). At present, the end customers on energy demand side have gradually become an aggregation of various forms of

\footnotetext{
* Correspondence: ningzhang@tsinghua.edu.cn

${ }^{1}$ Department of Electrical Engineering, Tsinghua University, Haidian District, Beijing 100084, China

Full list of author information is available at the end of the article
}

energy consumption such as energy storage, combined cooling, heat and power (CCHP) and load, which have self-coordination abilities. When the energy supply cannot meet the demands of the end customers in MES, the end customers need to respond in various forms to ensure the balance of energy supply and demand. It is necessary to explore the implementation mechanism and incentive mode of IDR, perform simulations to verify the effectiveness of the strategies, and solve the problems such as lack of supporting tools for the operation of IDR. In such cases, the efficiency of energy use on the customer side can be improved and the integrated energy service strategy can be effectively supported.

Traditional demand response is a mechanism in which customers dynamically change their electricity consumption behavior in response to time-of-use electricity price signals or real-time dispatching instructions to reduce critical-peak demand and transfer power consumption between different time periods. However, in the demand response oriented to multi-energy coordination, energy consumers response not only by reducing energy consumption or opting for off-peak energy consumption but 
also by changing the type of the consumed energy. With the rapid development of MES, all types of energy loads can participate in demand response.

IDR can break the boundaries between different types of energy sectors to realize a deep response to resources on the demand side. The values of IDR mainly include: 1) Improving the economic efficiency of the energy system. IDR enables multiple types of energy to participate in the optimization of demand response, which leads to a larger optimization space and further improves the benefit for customers. The IDR considers the conversion between various types of energy and thus raises the consumption of renewable energy resources [1]. At the same time, a deeper demand response can reduce the required investment of power grid. 2) Improving the safety of the energy system. Through the conversion between various types of energy, the IDR can reduce critical-peak load, maintain the transient balance of the system, improve the consumption of renewable energy, and further improve the safety of the system. 3) Mining the potential of demand response resources. With IDR, customers can conduct demand response more flexibly, and thus, the potential of demand response can be fully explored and the capacity of demand response resources can be improved.

At present, the research on demand response mainly focuses on the traditional demand response in power system, while the research on the analytical technique, evaluation method and implementation mechanism of IDR is not thorough and comprehensive enough. Different types of demand response resources have different dynamic time constants and control time scales, whereas establishing mathematical models for energy equipment under different time scales is a serious problem due to large-scale and high-complexity. The steady-state characteristics in a long time scale and the transient characteristics in a short time scale of various types of resources are also different. Therefore, it is necessary to study the optimal operation and control methods under different time scales and conditions of state dependence. Demand response is not a problem of one single time snapshot but a continuous optimization problem with temporal coupling. In addition, with a large scale of various demand response resources connected and reacted to the grid, the separated operation and management modes of traditional energy systems will be significantly changed, and the original supply-demand balancing mechanism, market mechanism and price mechanism are no longer applicable. Therefore, researchers worldwide are currently working to establish a scientific analysis framework and implementation mechanism for IDR.

Taking the traditional demand response in power system as a starting point, this paper first reviews the research on the fundamental theory, framework design and potential estimation of demand response in power system. The practical cases and software development of demand response are then introduced. Finally, the current theoretical research and application of IDR are assessed. The overall structure of the paper is shown in Fig. 1.

\section{Fundamental theory and framework design of demand response}

\subsection{Fundamental theory}

Demand response is an important means for the new-generation energy systems to deal with power generation uncertainty and load demand fluctuation [2]. Demand response is a mechanism in which power customers dynamically change their electricity consumption behavior in response to time-of-use electricity price signals or real-time dispatching instructions to reduce critical-peak demand and transfer power consumption between different time periods. The benefits of demand response can be significant. On the one hand, it can effectively reduce the peak load of the power system and delay the investments required for new generation units and transmission lines. On the other hand, it can improve the consumption of renewable energy and reduce the adjustment and start-up/shut-down costs of thermal power units during the off-peak periods, which also improves the safety of power system operation.

According to the different types of signals given to the demand side, demand response can be divided into price-based and incentive-based demand response. Price-based demand response can be further sub-divided into time-of-use price, real-time price, critical-peak price, multi-step price, etc. Incentive-based demand response can be sub-divided into direct load control, interruptible load, demand-side bidding, emergency demand response [3], etc. Due to the lack of price signal and market mechanism to promote demand response in China, demand response has been mainly realized by other means such as technology, administration and subsidies, including peak shifting, improvement of production process, cooling/heat storage, adjustment of production time and promotion of electricity-saving equipment, without fully considering and mobilizing the initiatives of customers. However, developed countries, such as the United Kingdom and the United States, which have fully developed their electricity markets, have implemented various demand response projects that effectively control the peak load of the systems. For example, in Europe, which has eight major regional electricity markets, demand response projects in each country can reduce the peak load by $2.9 \%$ on average. Existing research on demand response mainly focuses on two aspects: the optimal operation of power system 

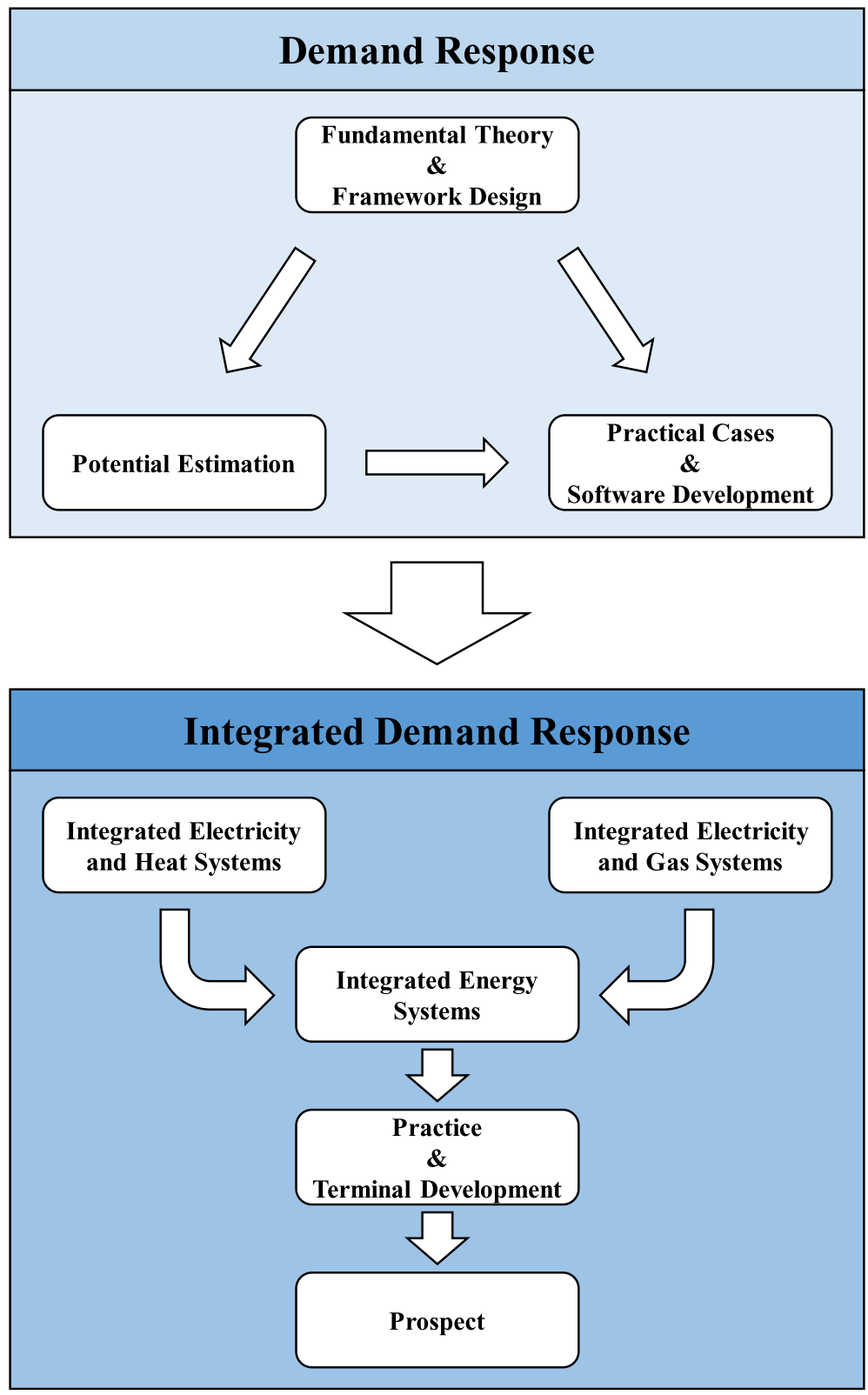

Fig. 1 Overall structure of the paper

considering demand response, and the optimal strategy for customers to participate in demand response according to external signals. From the viewpoint of system, through the optimal allocation of demand response resources, the objectives including minimum total operating cost [4], minimum network loss [5], maximum consumption of renewable energy [6], maximum social welfare can be achieved under certain constraints. The modeling methods of demand response include those based on the elasticity coefficient of electricity price [7] and considering the rebound effect of direct load control [8]. The considered demand response resources include residential electric water heaters [9], air conditioners
[10], distributed energy storage devices [11] and electric vehicles [12]. From the view point of customers, they will receive the electricity price signals from the electricity market or the suppliers. Considering the comfort of electricity consumption, the load aggregation and energy management optimization are realized for various types of electrical equipment including roof photovoltaics [13] and energy storage devices in different ranges, e.g., households [14], buildings [15] and residential areas.

\subsection{Framework design}

Demand response has developed from manual to semi-automatic and finally to full-automatic, and its 
effectiveness, reliability and flexibility have been greatly improved [16]. In the aspect of system framework design of demand response, reference [17] proposes a predictive control scheme of automatic demand response mechanism, which mainly considers the distributed energy connected to power grid, supports large-scale implementation of demand response projects, and can reflect the planning stage, real-time operation, financial settlement and verification of energy and services in the process. An integrated framework of communication and control of demand response is introduced in [18], and a meter gateway architecture is proposed to realize centralized load management and control by means of energy aggregators, equipment switches and intelligent electric equipment. Reference [19] proposes a demand response framework which can be applied to a home local area network (LAN) as a hardware architecture connecting the energy management system and the equipment interface unit to realize home demand response. In the process of acquiring data of power consumption and executing local load control, the communication between the equipment interface unit and the demand response system can be realized. The research team of the University of California, Berkeley subsequently proposes a framework named "Information-centric energy infrastructure", and its main purpose is to packet dispatch and control various types of distributed energy, load or energy storage systems to form energy subnets with different functions. Each energy subnet interacts with others through interfaces named Intelligent Power Switches in order to combine intelligent communication protocol with energy transmission in a common framework and realize the basic framework of cooperative control of various distributed energy sources, thus laying a solid foundation for the development of Energy Internet [20, 21].

\section{Potential estimation of demand response}

Potential estimation of demand response is to quantitatively estimate the load capacity that are able to participate in demand response. It is a prerequisite for quantitative analysis of demand response, and is the theoretical basis for practical application and software development of demand response.

Data mining of the real-time power consumption of customers is currently a hot research topic in the field of demand response potential estimation. Its core technique is clustering algorithm, including direct clustering and indirect clustering [22]. The direct clustering is performed on the data of power consumption itself, and various types of clustering techniques have been studied, including K-means [23], fuzzy K-means [24], agglomerative hierarchical clustering [25], self-organizing map (SOM) [26], support vector clustering [27] and subspace clustering [28]. Various types of indexes have been used to quantitatively evaluate the effect of clustering, including Clustering Dispersion Indicator (CDI), Scatter Index (SI), Davies-Bouldin Index (DBI) and Mean Index Adequacy (MIA) [29]. In order to deal with the challenges brought by the large quantity of electricity consumption data with high dimensionality, research on data dimensionality reduction has been carried out. The indirect clustering is performed on the data after dimensionality reduction instead of the original data itself. Dimensionality reduction approaches can be classified into feature extraction based methods and time series based methods. Feature extraction refers to mapping a high-dimensional data to a low-dimensional space, which includes linear dimensionality reduction method such as Principal Component Analysis (PCA) [30], and non-linear dimensionality reduction techniques such as Sommon Mapping, Curvilinear Component Analysis (CCA) [26] and deep learning [31]. Since the data of electricity consumption is essentially a time series, there are also some studies applying the idea of time series analysis to the data mining of electricity consumption, such as Discrete Fourier Analysis [32], Discrete Wavelet Analysis [33], Symbolic Aggregate Approximation [34] and Hidden Markov Model [35].

Clustering analysis of the data of electricity consumption mainly aims at obtaining typical electricity consumption patterns of customers and then estimating the potential of demand response. Furthermore, the classification of customers with similar electricity consumption patterns can reduce the high cost of identifying the massive data of electricity consumption one by one [36, 37], and also lay a foundation for customer classification modeling and implementation of demand response. Apart from the research on unsupervised clustering techniques, there are also some studies of supervised classification techniques. Based on the load profiles labeled by the customer pattern or electric equipment, the physical meaning indicated by the data of power consumption is analyzed through decision tree [38], logistics regression [39] and other techniques. Besides, the potential estimation of customer demand response also provides a basis for the settlement of demand response.

\section{Practical cases and software development of demand response}

\subsection{Practical projects worldwide}

Many power grids worldwide have introduced demand response. In 2012, Beijing was chosen as one of the first pilot cities for demand side management (DSM) in China and made a preliminary attempt on DSM. In 2015, Beijing took the lead in establishing the demand response mechanism named "Initiative Response, Load Aggregation" in China. It also issued the Notice of 
Beijing Development and Reform Commission on the Recruit of Demand Response Load Aggregators and Power Consumers for Beijing's Comprehensive Pilot DSM Program, and first 26 organizations were chosen as the "Demand Response Load Aggregators for Beijing's Comprehensive Pilot DSM Program in 2015". Execution process of the demand response program in Beijing is shown in Fig. 2. On July 26, 2016, Jiangsu Province successfully implemented province-wide demand response for the first time. This activity consisted of two modes of demand response: agreed response and real-time response, with a total of 3154 participating customers. The agreed response was wholly performed by business customers, including 248 ordinary consumers and 24 load aggregators. The real-time response was mainly performed by air conditioning loads from 1871 participants, including 1550 non-domestic customers and 321 domestic customers. According to the preliminary statistics, the actual agreed response load was 3.31 million kilowatts and the real-time response load was 0.214 million kilowatts, i.e., 3.52 million kilowatts in total. The PJM power grid in the United States has achieved remarkable benefits from demand response, the capacity of which accounts for about $6 \%$ of the peak load of the whole network. In September 2013, PJM deployed nearly 6 million kilowatts of demand response sources, which saved about 11 billion US dollars on electricity bills for the customers in that year. In terms of dynamic demand response, real-time automatic demand response system has been established at Zhangjiagang Free Trade Zone and Yangtze Metallurgical Industrial Park in Jiangsu Province. A total of 868 pieces of electric equipment owned by 276 enterprises in the park can automatically make response decisions according to real-time power consumption under the control instructions from the demand response platform. Without affecting the

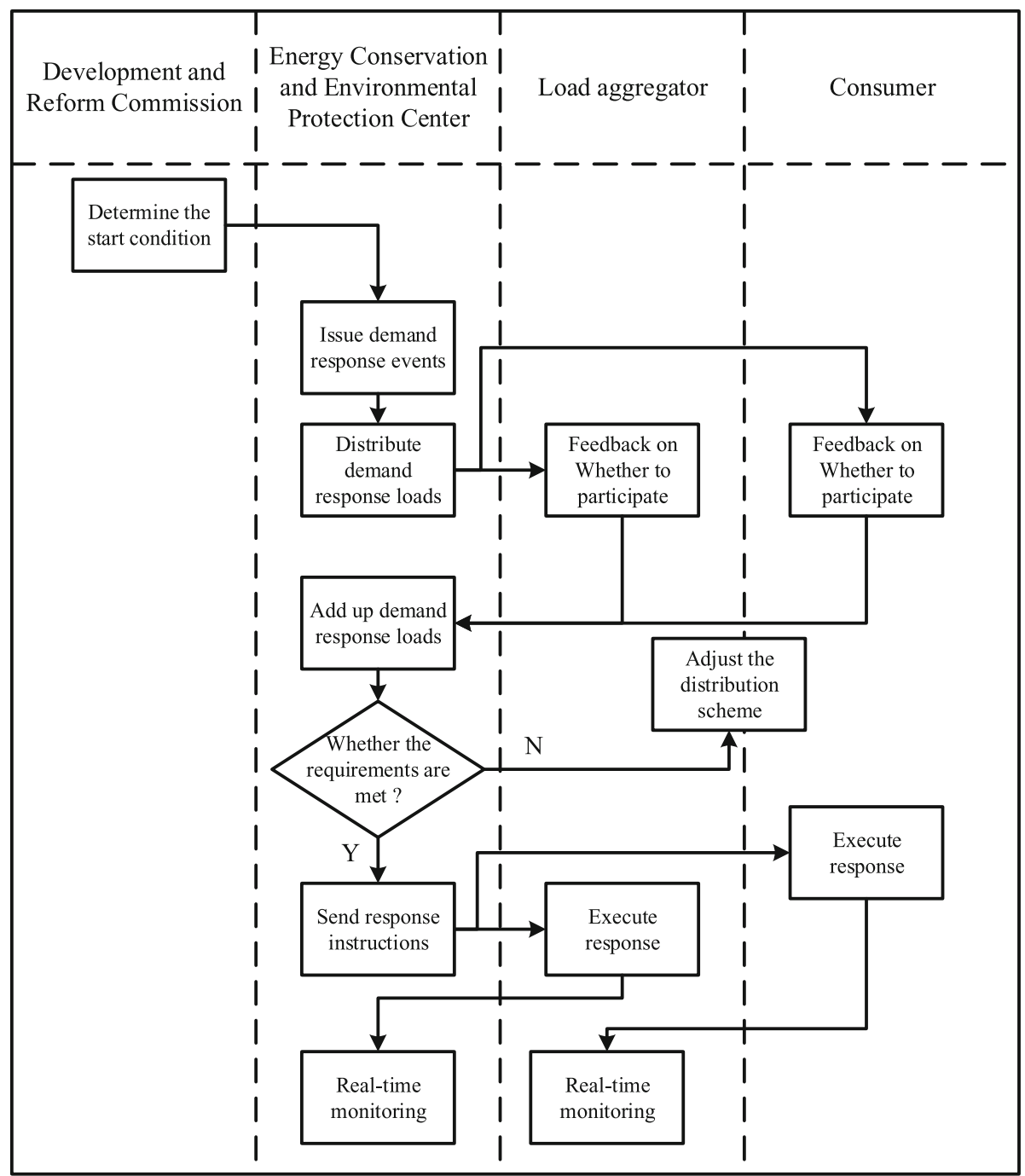

Fig. 2 Execution process of the demand response program in Beijing 
normal production of the enterprises, the total demand of the park can be reduced by $558,000 \mathrm{~kW}$ in just one second by suspending production, load reduction or other means, thereby realizing a second-level dynamic demand response.

Promoting demand response is also an important move for demand side revolution in China. The issue of Several Opinions of the CPC Central Committee and the State Council on Further Deepening the Reform of the Electric Power System (ZF [2015] No. 9) in March 2015, officially kicked off a new round reform of power system in China. The opening of the retail electricity market is an important part of the new round of reform, which will result in many new market members such as electricity suppliers and load aggregators. Demand response, as a low-cost, flexible-deployment, and high-quality resource, can incorporate into the electricity market through flexible business models, such as reducing the electricity bill by responding to the time-of-use price, and providing auxiliary services such as peak shaving and reserve. It can be predicted that in the near future, the resources and potential of demand response will be widely motivated and demand response will become a brand-new and non-negligible factor in the operation of power system.

\subsection{Software development and application}

As for the software development and application of demand response system, Pacific Gas and Electric Company implements a demand-side bidding project based on an automated platform. Through the application of automation technology and communication technology, it coordinates the control of consumers and distributed energy resources to reduce the peak load. The "ITM" project of the Kema Laboratory in the Netherlands uses time-of-use distribution technology and incentive mechanism to mitigate the impact of electric vehicles on the power grid. FRANKE GMKP, a German company, develops the FRANKE GMKP Demand Controller System that can predict the peak load at the next moment through trend analysis, and make adjustments accordingly such as power changing, delay or load shedding to realize automatic time-interval based control of the energy system [40]. Japan has set up a number of demonstration projects for the comprehensive utilization of multiple energy resources in Aichi, Kyoto, Hachinohe, Kyotango, Shimizu and Sendai with the support of the New Energy and Industrial Technology Development Organization (NEDO). In terms of control, a master-slave structure is adopted to maintain the power balance of the system, which uses the upper energy management system to optimally dispatch the distributed energy resources and energy storage devices. Generally, these distributed energy resources do not have the ability of "plug and play". The "i-japan (Smart Japan) Strategy 2015" aims at integrating digital information technology into every corner of production and life to fully support the development of smart cities [41].

Domestically, in recent years, standards, such as GB/T 32672-2016 General Technical Specification of Power Demand Response Systems and GB/T 35681-2017 Functional Specification of Power Demand Response Systems, have been issued to provide guidance for the development of demand management systems on the demand side. Reference [42] focuses on the analysis of the communication framework of the demand response system. The study designs the system framework according to the characteristics of energy management and communication network. On such basis, the framework is compared with the traditional master-slave framework in the aspects of mode of framework, scalability, reliability, traffic analysis, delay problems, etc. The functional framework of comprehensive energy management system in Sino-Singapore Tianjin Eco-city established by State Grid Tianjin Electric Power Company is introduced in [43]. The developed comprehensive energy management system realizes the optimal utilization of the distributed energy resources, distribution networks, multiple loads and other resources in the park.

The described software development and application of demand response are summarized in Table 1.

\section{Integrated demand response}

In the traditional demand response in power system, customers respond to electricity price or incentives [44] and change their original power consumption patterns to gain additional benefits [45-47]. With the development of MES in which electricity, heat, natural gas and other forms of energy are coupled with each other, all types of energy customers are able to participate in demand response. The concept of IDR was clearly put forward for the first time in [48, 49]. In IDR, energy consumers response not only by reducing energy consumption or opting for off-peak energy consumption but also by changing the type of consumed energy.

The focus of the research on IDR can be divided into three categories: integrated electricity and heat systems, integrated electricity and gas systems, and integrated energy systems.

\subsection{Integrated electricity and heat systems}

A typical type of integrated electricity and heat systems is the electric heating system for residential buildings. The thermal inertia of the heat load, the passive heat storage characteristics of the building and the body comfort of the customers are usually considered in the research on IDR of building heating system. Heat pumps and heat storage systems are generally considered as the 
Table 1 Software development and application of demand response worldwide

\begin{tabular}{|c|c|c|c|c|}
\hline Project or System & Country & Supporter & $\begin{array}{l}\text { Technology or } \\
\text { Method }\end{array}$ & Achievements or Outlooks \\
\hline Demand-side bidding project & USA & $\begin{array}{l}\text { Pacific Gas and Electric } \\
\text { Company }\end{array}$ & $\begin{array}{l}\text { Automation } \\
\text { technology and } \\
\text { communication } \\
\text { technology }\end{array}$ & $\begin{array}{l}\text { Coordinating the control of consumers and } \\
\text { distributed energy resources to reduce the peak } \\
\text { load }\end{array}$ \\
\hline The "ITM" project & Netherlands & Kema Laboratory & $\begin{array}{l}\text { Time-of-use } \\
\text { distribution } \\
\text { technology and } \\
\text { incentive mechanism }\end{array}$ & $\begin{array}{l}\text { Mitigating the impact of electric vehicles on the } \\
\text { power grid }\end{array}$ \\
\hline $\begin{array}{l}\text { FRANKE GMKP Demand } \\
\text { Controller System }\end{array}$ & German & FRANKE GMKP & Trend analysis & $\begin{array}{l}\text { Predicting the peak load at the next moment, and } \\
\text { making adjustments accordingly such as power } \\
\text { changing, delay or load shedding to realize } \\
\text { automatic time-interval based control of the en- } \\
\text { ergy system }\end{array}$ \\
\hline $\begin{array}{l}\text { Demonstration projects for } \\
\text { the comprehensive utilization } \\
\text { of multiple energy resources }\end{array}$ & Japan & $\begin{array}{l}\text { New Energy and Industrial } \\
\text { Technology Development } \\
\text { Organization (NEDO) }\end{array}$ & Master-slave structure & $\begin{array}{l}\text { Using the upper energy management system to } \\
\text { optimally dispatch the distributed energy } \\
\text { resources and energy storage devices }\end{array}$ \\
\hline $\begin{array}{l}\text { The "i-japan (Smart Japan) } \\
\text { Strategy } 2015 \text { " }\end{array}$ & Japan & Government & $\begin{array}{l}\text { Digital information } \\
\text { technology }\end{array}$ & Fully supporting the development of smart cities \\
\hline $\begin{array}{l}\text { Comprehensive energy } \\
\text { management system }\end{array}$ & China & $\begin{array}{l}\text { State Grid Tianjin Electric } \\
\text { Power Company }\end{array}$ & $\begin{array}{l}\text { Multi-stage energy } \\
\text { coordination control } \\
\text { method }\end{array}$ & $\begin{array}{l}\text { Realizing the optimal utilization of the distributed } \\
\text { energy resources, distribution networks, multiple } \\
\text { loads and other resources in the park }\end{array}$ \\
\hline
\end{tabular}

heating equipment. Reference [50] combines the electric heating system (i.e., heat pumps and electric resistance heaters) with heat storage (i.e., the passive heat storage of the building and the active heat storage of domestic hot water tanks) to evaluate the benefits of demand response in terms of energy consumption and operating cost, and to study the influence of the penetration rate of demand response among the customers. The reduction in carbon dioxide emission and its related cost by replacing condensing gas boilers with heat pumps for residential space heating and domestic hot water supply is analyzed in [51]. The study concludes that active and passive heat storage based demand response can greatly reduce the peak electricity demand, thus reducing the overall cost associated with carbon dioxide emission. Reference [52] adopts the linear programming method to optimize the demand response control of the electric space heating system with heat storage. The method combines the demand response of electric space heating and heat storage to minimize the total cost without sacrificing the comfort of consumers. Reference [53] proposes an optimal control scheme considering demand response for detached residential houses with a ground source heat pump and a heat storage system in cold climate, and calculates the minimum life cycle cost of the heat storage system. Three different control algorithms are considered: the algorithm based on real-time electricity price, the backward search algorithm based on previous electricity price, and the algorithm based on the prediction of future electricity price. Reference [54] introduces the application results of three control strategies for heat pumps in building energy consumption simulation, taking into account the factors including electricity price and the local electricity generation from photovoltaics. Taking into account the comfort of the customers, the analyzed control strategies cut electricity bill and improve renewable energy consumption. Reference [55] considers thermal models with different complexity for intelligent residential buildings to analyze the influence of thermal inertia on the benefit of the customers under demand response. A mixed integer linear programming model is used to minimize the electricity consumption of the heat load. Reference [56] analyzes the operation mode of heat pumps or combined underfloor heating and heat storage system, and how the system affects and ensures the thermal comfort of the customers under the demand response. The study aims at flattening the electricity load curve by turning off the heat pumps during the peak periods. Also taking into account the thermal comfort of the customers, reference [57] studies a detailed physical model for high-resolution simulation of load pattern change due to different electro-thermal technologies with different thermal inertia characteristics in different buildings and their impacts on the disaster recovery control strategies. Reference [58] proposes a resilient strategy for optimal demand response control based on the management of highly distributed electricity loads, which regulates the operation points of the heat pumps to control the total electricity demand. The strategy contributes to maintaining the stability of the voltage as well as the comfort of the customers.

Another typical type of integrated electricity and heat systems is the regional combined heat and power $(\mathrm{CHP})$ 
system, such as a CHP unit in a microgrid. The IDR strategy of the regional CHP system often takes into account the peak shifting rather than load shedding (e.g., reducing the heat load using the thermal inertia of the buildings), and also considers more types of optimization objectives (e.g., emissions). Some studies also model the demand response as a virtual power generation unit. Reference [59] investigates a model-predictive control (MPC) strategy based on demand response for the intelligent control of a micro-CHP system. A distributed energy management method for the coordinated operation of CHP systems based on demand response is proposed in [60]. The demand response is modeled as a virtual power generation unit. A distributed iterative algorithm based on dynamic direction searching is also proposed, in which information exchange between adjacent microgrids is limited to Lagrange multipliers and the expected amount of the energy to purchase. Reference [61] considers the dynamics and constraints of both supply and demand sides of the system, and establishes a comprehensive model including the electric heating systems (heat pumps and auxiliary resistance heaters) affected by demand response schemes, so as to accurately evaluate the benefits and interactions of both supply and demand sides under the demand response. A novel multi-objective (operating costs + emissions) optimal operation scheme of a CHP based microgrid is presented in [62], considering the energy storage system, three types of thermal power units and demand response. The demand response is also treated as a virtual power generation unit, and the model is a simple mixed integer programming problem. Reference [63] studies the optimal dispatch of an isolated microgrid using domestic hot water provided by a solar thermal system. The method estimates the hourly hot water load, proposes and simulates different demand response strategies to minimize the dispatch cost of the energy system. The control of electric water heaters is analyzed in [9]. Taking into account the wind power generation, the study discusses five control methods and six optimization objectives, including the comfort of the customers, safety (i.e., keeping water temperature within a safe range) and load shifting from the peak periods to the off-peak periods. Considering the cost of the customers, the impact of energy utilization on the environment and the expansion of power generation capacity, a multi-objective predictive control strategy is proposed in [64]. The demand response strategy significantly reduces the peak load, and adding a heat storage tank can further reduce the required generation capacity. References $[65,66]$ analyze the short-term hourly dispatch strategy for industrial and commercial customers using CHP units, power-only units and heat-only units. Through demand response, the electricity and heat demands of the customers can be met with the lowest cost, and the response load can be transferred between different time periods without curtailing load. Aiming at minimizing the costs and emissions, a multi-objective optimal energy management model is proposed in [67]. The electricity and heat demands in the microgrids are efficiently satisfied by coordinating various types of energy resources. Reference [68] introduces the current application status of heat storage in DSM, focusing on the relationship between different types of heat storage systems and the characteristics of DSM.

\subsection{Integrated electricity and gas systems}

The integrated electricity and gas systems are typically at power transmission network level, so the research on IDR in integrated electricity and gas systems often takes into account the detailed network models of the electricity and natural gas networks. The demand response is either modeled as a virtual power plant or modeled by simple peak-shifting constraints. The steady-state coordinated operation of the electricity and natural gas networks aiming at maximizing the profits considering demand response is studied [69]. The demand response is modeled as a virtual power plant. A bi-level mixed integer programming optimization model is also established, in which the upper layer represents the cooperative operation to maximize the profits, while the lower layer simulates the liquidation process of the day-ahead market. A stochastic day-ahead scheduling model for integrated electricity and gas systems is proposed in [70], and is used to schedule the hourly power generation and the demand response resources. Flexible resources with high ramp rate are used to cope with the volatility of renewable energy. Reference [71] studies the role of demand response in the stochastic day-ahead scheduling optimization of integrated electricity and gas systems. The proposed coordinated stochastic model takes into account the stochastic outages of the units and the transmission lines, as well as the stochastic errors of the forecasted day-ahead hourly loads. The uncertainty of the system is simulated by the Monte Carlo method, and the linearized natural gas network constraints are incorporated into the stochastic model. Considering demand response and the uncertainty of wind power, an interval optimization based coordinated operation strategy of integrated electricity and gas systems is proposed in [72]. The gas and electricity infrastructures are modeled in detail, including the non-linear characteristics of pipeline gas flows and compressors.

\subsection{Integrated energy systems}

Since integrated energy systems take into account the coupling among various forms of energy such as electricity, gas, heat and cooling, more energy conversion and 
storage devices and technologies can be considered and more flexible resources can be used for carrying out the IDR. In order to simulate the interaction between the electricity and natural gas networks in distribution systems, reference [73] models the residential customers in MES and proposes an energy management system based on the reinforcement learning algorithm to encourage customers to participate in the DSM plans, thus reducing the peak loads of the electricity and natural gas networks. A novel design and short-term optimal planning method for a CCHP system using a solar dish Stirling heat engine driven heat pump is proposed in [74]. The method utilizes an absorption tower and a heat storage tank to absorb and store the collected heat and continuously supply heat during days with insufficient sunshine and at night. Reference [75] evaluates the economic dispatch problem of a hybrid photovoltaics/battery/fuel cell energy system considering demand response. The demand response strategy is to transfer a certain amount of load from the peak periods to other periods to flatten the load curve and minimize the total cost. Batteries and heat storage tanks are also used to assist in the energy supply during the peak periods to reduce the cost. References $[76,77]$ use discrete heat balance differential equations to model the coordinated operation of a CCHP based microgrid system. Reference [16] assesses the technologies of IDR in integrated energy systems, introduces the general situations of the domestic and foreign engineering projects, and finally discusses the key issues and potential research topics of IDR in integrated energy systems.

For the research on IDR in integrated energy systems, the concept of energy hub (EH) $[78,79]$ has been widely introduced. Most of the studies model the integrated energy systems as an EH. Reference [80] develops a multi-objective (cost and environment) operation optimization model of $\mathrm{EH}$ in the presence of demand response. The weighted sum method is adopted to solve the multi-objective model and the fuzzy technique is used to select the optimal compromise solution. Demand response using load shifting flattens load curve and reduces total cost and emission of EH. Reference [81] combines the supply-side characteristics of the EH with the demand-side flexibility brought by the demand response schemes, and models the energy supply system of the building as an EH with its heat demand modeled according to the laws of thermodynamics. The effects of different demand response schemes (load shedding and shifting) with and without wind power and energy storage in the integrated energy systems are compared in [82]. The EH model is used to simulate the wind power, energy storage and demand response in electricity and natural gas infrastructures. Reference [83] proposes a 2 $\mathrm{m}+1$ point estimation probabilistic scheduling scheme for multi-input multi-output $\mathrm{EH}$, and studies the impact of the response heat and electricity loads on reduction of the total cost and the impact of the participation of different equipment on supplying multi-energy loads. Reference [84] proposes a residential EH model, which consumes electricity, natural gas and solar radiation at the input ports to meet the electricity, heat and cooling demands at the output ports. In order to improve the operational flexibility of the $\mathrm{EH}$, an inclusive demand response strategy including load shifting, load shedding and flexible heat load modeling is adopted. A mathematical model framework for the optimal planning of $\mathrm{EH}$ considering the operation constraints is provided in [85]. Both deterministic and stochastic objective functions are given considering the wind power, electricity price and electricity demand. Wind turbines, energy storage and demand response are considered in the $\mathrm{EH}$. Reference [86] introduces a way to integrate demand response and energy storage into the existing multi-energy network analysis and modeling method. The study concludes that demand response has a similar effect to energy storage and thus demand response can be modeled as an equivalent energy storage unit. The optimal operation of integrated energy systems considering wind farms, electric heat storage systems, demand response, electricity market and thermal energy market is studied in [87]. A stochastic programming method is adopted to model the uncertainties of demands, market prices, wind speed, etc. Reference [88] attempts to develop a general stochastic optimization modeling framework to solve the dispatch problem of EH with wind power while considering demand response through load shifting. The Monte Carlo sampling method is used to generate the data of wind power and load scenarios. In [89], the EH is regarded as an equivalent node of the distribution networks, and the operation of $\mathrm{EH}$ is optimized based on the objective function considering economy, greenhouse gas emission, reliability and efficiency. The uncertainties of wind power and real-time pricing market are also considered. A value evaluation method of $\mathrm{EH}$ with energy converters, storage and DSM is proposed in [90]. Considering the flexibility of $\mathrm{EH}$ in changing output powers, the Monte Carlo simulation method is adopted to evaluate its economic value. A robust optimization model based on EH model for integrated energy systems is established in [91]. By optimizing the energy flows in the $\mathrm{EH}$, the IDR can be realized while the load demands of the $\mathrm{EH}$ are most economically met.

In other studies, integrated energy systems are modeled as multiple EHs, and the game and cooperative operation among these EHs with IDR are investigated. In [92], the traditional EH model is improved and an advanced model named "smart energy hub" is proposed in a smart environment. A cloud computing framework is 
then provided for a group of smart EHs and the game theory is used to model the DSM of smart EHs. Reference [93] extends the existing demand response to IDR and the interaction among smart EHs with IDR is defined as a non-cooperative game. The goal of the game is to maximize the profits of natural gas and electricity utility companies, thus reducing the cost of the customers. The proposed game model is an ordinal potential game with a unique Nash Equilibrium. An example of EH combining distributed energy sources/CCHP, renewable energy and energy storage is designed, and an operation model of regional multiple energy producers is subsequently proposed in [94]. The energy exchange between EHs is based on the energy buses, including buses for electricity, heat and cooling.

\subsection{Application and terminal development of IDR}

In order to fully explore the potential of demand response resources, many countries around the world encourage the development of integrated energy systems and the research and engineering applications of IDR. In 2001, the U.S. government introduced the concept of "Power Grid 2030" [95], and the U.S. National Nature Fund System Center put forward the future renewable energy distribution and management system $[96,97]$ in 2008. Through the coordination of various household equipment including air conditioning, roof photovoltaics, heat pumps, etc., IDR can be effectively implemented. In Europe, the German Ministry of Economic Affairs and Energy put forward the "E-Energy" project in 2008. Based on the information exchange technology, the objective of the project is to build a future MES through information exchange and coordination between energy systems and household equipment. By coupling electricity, heat and natural gas, the home energy management system can carry out IDR, thus greatly improving the efficiency and reliability of customers' energy use [98]. The Ministry of Energy and Climate Change and various companies in the United Kingdom jointly funded a project in 2015 to study integrated energy systems in Birmingham. The objective of the project is to efficiently meet the electricity, natural gas and heat demands while implementing IDR $[99,100]$. The power system laboratory of the Swiss Federal Institute of Technology in Zurich has proposed a smart EH model which is the core method for studying IDR [101-103]. In 2015, China put forward the construction vision of "Internet + Intelligent Energy" and proposed that the coupling of electricity, heat and natural gas is the foundation of the construction of Energy Internet [104]. Shanghai Mansion has made a demonstration for the implementation of IDR. The energy system of the mansion consists of a CHP unit, an air conditioning system, a cooling storage system, a ground-source heat pump system and a gas boiler. The energy management system of the mansion can optimize the energy consumption according to the behaviors of the customers and the TOU electricity price in Shanghai. By peak shaving, valley filling and optimizing energy consumption, the energy efficiency can be improved by $22 \%$ and the operating cost can be reduced by 10 million USD per year.

In terms of IDR terminal, the YYHFK2000G terminal developed by Xuchang Relay Group adopts GPRS/ CDMA communication technology and supports various modes of hardware connection, with power consumption of the whole machine being less than $3 \mathrm{~W}$. The demand side response terminal developed by Nari Group Corporation has the characteristics of being friendly to the power grid and can meet the need for regulating system peak and frequency; however, the economic efficiency and the universality of accessible equipment need to be improved. The demand-side response terminals of EnerNOC and Honeywell companies are integrated into the building automation systems leading to some economic benefits, though it is difficult for their terminals to gain access to decentralized demand-side equipment.

\section{Prospect of IDR}

In the current optimization models for MES with IDR, IDR is commonly modeled by several simple constraints which have been widely used for the traditional demand response in power system. The characteristics of IDR, e.g., the energy conversion and coupling, are not able to be fully reflected by the model of the traditional demand response. Future work should focus more on the modeling and optimization of IDR itself, establishing a specialized and detailed model for IDR with full consideration of its characteristics. The optimization problem concerning IDR in MES should not be limited to the optimal scheduling and operation problems, and more research need be dedicated to the optimal planning of MES with IDR, reliability analysis of MES with IDR, and so on.

Although a lot of research on the optimal scheduling of IDR has been carried out, studies of its market mechanism are few. Therefore, there is an urgent need to develop a pricing mechanism for IDR so that the benefits or profits created by IDR can be reasonably distributed among multi-energy suppliers and customers. As a result, multi-energy suppliers are inspired to organize IDR programs and provide the data and technical support, and customers are motivated to change their energy consumption patterns by load shaving, load shedding and so on, which further contributes to the benefit and safety improvements of MES.

As for the application of IDR, the practice and terminal development are still in their early phases in China. The terminals for IDR should have the functions 
such as data acquisition, data storage, data processing, input/output control, self-maintenance, terminal interaction and user simulation. More efforts need be made to the improvements of the hardware connection mode, power consumption, peak/frequency modulation capability, power grid friendliness, economic efficiency and equipment accessibility of the IDR terminals.

\section{Conclusion}

Demand response in power system can effectively reduce system peak load and delay the required investments of additional generation units and transmission lines. In addition, it can improve the consumption of renewable energy and reduce the adjustment and start-up/shut-down costs of thermal power units during off-peak periods, which further improves the operation safety of the power grid. With the rapid development of integrated energy systems, IDR can break the boundaries between different types of energy sectors, realize the deep response of demand side resources, and further improve the economic efficiency, safety and flexibility of the energy system. Taking the traditional demand response in power system as a starting point, this paper reviews the research on the fundamental theory, framework design and potential estimation of demand response in power system, introduces the practical cases and software development of demand response, and finally assesses the current theoretical research and application of IDR. The findings can provide good reference and help researchers to establish scientific analysis frameworks and implementation mechanisms for IDR.

\section{Acknowledgements}

Not applicable.

\section{Funding}

This work was supported by the Major Smart Grid Joint Project of National Natural Science Foundation of China and State Grid (No. U1766212) and International (Regional) Joint Research Project of National Natural Science Foundation of China (No. 71961137004).

\section{Availability of data and materials}

Data sharing not applicable to this article as no datasets were generated or analyzed during the current study.

\section{Authors' contributions}

$\mathrm{WH}$, as the first author, carried out the literature review and drafted the manuscript. NZ, as the corresponding author, conceived of the manuscript and revised the draft of the manuscript. CK, ML and MH, as the technical advisors, helped to revise the manuscript. All authors read and approved the final manuscript.

\section{Competing interests}

The authors declare that they have no competing interests.

\section{Author details}

'Department of Electrical Engineering, Tsinghua University, Haidian District, Beijing 100084, China. ${ }^{2}$ State Grid (Suzhou) City \& Energy Research Institute, Suzhou, China.
Received: 16 April 2019 Accepted: 14 May 2019

Published online: 30 May 2019

\section{References}

1. Behboodi, S., Chassin, D. P., Crawford, C., et al. (2016). Renewable resources portfolio optimization in the presence of demand response. Applied Energy, $162,139-148$

2. Jiangsu built second-level peak-shaving power plant: the first real-time automatic demand response for industrial electric equipment in the world[Z/OL]. Jiangsu Demand Side Management Platform. http://www. jsdsm.gov.cn/dsmsite/znyq/2129.jhtml. Accessed 3 Dec 2019.

3. Zhao, H., Zhu, Z., \& Yu, E. (2010). Study on demand response markets and programs in electricity markets. Power System Technology, (5), 146-153 (in Chinese).

4. Bie, Z., Hu, G., Xie, H., \& Li, G. (2014). Optimal dispatch for wind power integrated systems considering demand response. Automation of Electric Power Systems, 38(13), 115-120 (in Chinese).

5. Hu, W., Chen, Z., Bak-Jensen, B., et al. (2014). Fuzzy adaptive particle swarm optimisation for power loss minimisation in distribution systems using optimal load response [J]. IET Generation, Transmission \& Distribution, 8(1), 1 10.

6. Wang, B., Liu, X., \& Li, Y. (2013). Day-ahead generation scheduling and operation simulation considering demand response in large-capacity wind power integrated systems. Proceedings of the CSEE, 33(22), 35-44 (in Chinese).

7. Yu, R., Yang, W., \& Rahardja, S. (2012). A statistical demand-price model with its application in optimal real-time price. IEEE Transactions on Smart Grid, 3(4), 1734-1742.

8. Han, X., Sossan, F., Bindner, H. W., et al. (2014). Load kick-back effects due to activation of demand response in view of distribution grid operation. In Innovative smart grid technologies conference Europe (ISGT-Europe), 2014 IEEE PES (pp. 1-6). Istanbul: IEEE.

9. Pourmousavi, S. A., Patrick, S. N., \& Nehrir, M. H. (2014). Real-time demand response through aggregate electric water heaters for load shifting and balancing wind generation. IEEE Transactions on Smart Grid, 5(2), 769-778.

10. Gao, C., Li, Q., \& Li, Y. (2014). Bi-level optimal dispatch and control strategy for air-conditioning load based on direct load control. Proceedings of the CSEE, 34(10), 1546-1555 (in Chinese).

11. Wang, Z., Gu, C., Li, F., et al. (2013). Active demand response using shared energy storage for household energy management. IEEE Transactions on Smart Grid, 4(4), 1888-1897.

12. Liu, W., Wu, Q., Wen, F., \& Xue, Y. (2014). A market mechanism for participation of electric vehicles and dispatchable loads in distribution system congestion management. Automation of Electric Power Systems, 38(24), 26-33 (in Chinese).

13. Wang, Y., Lin, X., \& Pedram, M. (2014). Adaptive control for energy storage systems in households with photovoltaic modules [J]. IEEE Transactions on Smart Grid, 5(2), 992-1001.

14. Liu, W., Wu, Q., Wen, F., et al. (2014). Day-ahead congestion management in distribution systems through household demand response and distribution congestion prices. IEEE Transactions on Smart Grid, 5(6), 2739-2747.

15. Sivaneasan, B., Kumar, K. N., Tan, K. T., et al. (2015). Preemptive demand response management for buildings. IEEE Transactions on Sustainable Energy, 6(2), 346-356.

16. Wang, J., Zhong, H., Ma, Z., et al. (2017). Review and prospect of integrated demand response in the multi-energy system. Applied Energy, 202, 772-782.

17. Lampropoulos, I., van den Bosch, P. P. J., \& Kling, W. L. (2012). A predictive control scheme for automated demand response mechanisms. In Innovative smart grid technologies (isgt europe), 2012 3rd ieee pes international conference and exhibition on. IEEE (pp. 1-8).

18. LeMay, M., Nelli, R., Gross, G., et al. (2008). An integrated architecture for demand response communications and control. In Hicss (p. 174). Waikoloa: IEEE.

19. Pipattanasomporn, M., Kuzlu, M., \& Rahman, S. (2012). Demand response implementation in a home area network: A conceptual hardware architecture. In Innovative smart grid technologies (ISGT), 2012 IEEE PES (pp. 1-8). Washington, DC: IEEE.

20. Wang, D. (2010). Application of incentive demand response in USA. Power Demand Side Management, 12(1), 74-77 (in Chinese).

21. Li, G., Liu, L., Fu, X., \& Yuan, R. (2014). DSM development in Finland. Power Demand Side Management, 16(1), 61-64 (in Chinese). 
22. Wang, Y., Chen, Q., Kang, C., et al. (2015). Load profiling and its application to demand response: A review. Tsinghua Science and Technology, 20(2), 117-129.

23. Zhao, L., Hou, X., Hu, J., Fu, H., \& Sun, H. (2014). Improved K-means algorithm based analysis on massive data of intelligent power utilization. Power System Technology, 38(10), 2715-2720 (in Chinese).

24. Zhang, S., Liu, J., Zhao, B., \& Cao, J. (2013). Cloud computing-based analysis on residential electricity consumption behavior. Power System Technology, 37(6), 1542-1546 (in Chinese).

25. Kwac, J., Flora, J., \& Rajagopal, R. (2014). Household energy consumption segmentation using hourly data. IEEE Transactions on Smart Grid, 5(1), 420-430

26. Chicco, G., Napoli, R., \& Piglione, F. (2006). Comparisons among clustering techniques for electricity customer classification. IEEE Transactions on Power Systems, 21(2), 933-940.

27. Chicco, G., \& Ilie, I. S. (2009). Support vector clustering of electrical load pattern data. IEEE Transactions on Power Systems, 24(3), 1619-1628.

28. Piao, M., Shon, H. S., Lee, J. Y., et al. (2014). Subspace projection method based clustering analysis in load profiling. IEEE Transactions on Power Systems, 29(6), 2628-2635.

29. Chicco, G. (2012). Overview and performance assessment of the clustering methods for electrical load pattern grouping. Energy, 42(1), 68-80.

30. Koivisto, M., Heine, P., Mellin, I., et al. (2013). Clustering of connection points and load modeling in distribution systems. IEEE Transactions on Power Systems, 28(2), 1255-1265.

31. Varga, E. D., Beretka, S. F., Noce, C., et al. (2015). Robust real-time load profile encoding and classification framework for efficient power systems operation. IEEE Transactions on Power Systems, 30(4), 1897-1904.

32. Zhong, S., \& Tam, K. S. (2015). Hierarchical classification of load profiles based on their characteristic attributes in frequency domain. IEEE Transactions on Power Systems, 30(5), 2434-2441.

33. Xiao, Y., Yang, J., Que, H., et al. (2014). Application of wavelet-based clustering approach to load profiling on AMI measurements. In Electricity distribution (CICED), 2014 China international conference on. IEEE (pp. 1537-1540).

34. Notaristefano, A., Chicco, G., \& Piglione, F. (2013). Data size reduction with symbolic aggregate approximation for electrical load pattern grouping. IET Generation, Transmission \& Distribution, 7(2), 108-117.

35. Albert, A., \& Rajagopal, R. (2013). Smart meter driven segmentation: What your consumption says about you. IEEE Transactions on Power Systems, 28(4), 4019-4030.

36. Wang, J., Ji, Z., Shi, M., Huang, F., Zhu, C., \& Zhang, D. (2015). Scenario analysis and application research on big data in smart power distribution and consumption systems. Proceedings of the CSEE, 35(8), 1829-1836 (in Chinese).

37. Zhao, T., Zhang, Y., \& Zhang, D. (2014). Application technology of big data in smart distribution grid and its prospect analysis. Power System Technology, 38(12), 3305-3312 (in Chinese).

38. Figueiredo, V., Rodrigues, F., Vale, Z., et al. (2005). An electric energy consumer characterization framework based on data mining techniques. IEEE Transactions on Power Systems, 20(2), 596-602.

39. McLoughlin, F., Duffy, A., \& Conlon, M. (2015). A clustering approach to domestic electricity load profile characterisation using smart metering data. Applied energy, 141, 190-199.

40. Xu, D., Liu, X., \& Fan, B. (2015). Efficient server provisioning and offloading policies for internet data centers with dynamic load-demand. IEEE Transactions on Computers, 64(3), 682-697.

41. Asano, H., Takahashi, M., \& Ymaguchi, N. (2011). Market potential and development of automated demand response system. In Power and Energy society general meeting, 2011 IEEE (pp. 1-4). San Diego: IEEE.

42. Zhou, Z., Cai, J., Shi, R., \& Qi, B. (2013). Review of demand response communication framework for smart grid. Electrotechnical Application, 32(S1), 68-74 (in Chinese)

43. Zhang, P., Li, G., Yu, J., Chen, Y., \& Lu, W. (2017). Research and application of integrated energy management in smart distribution and utilization power park. Distribution \& Utilization, 34(7), 34-40 (in Chinese).

44. Zhang, Q., \& Li, J. (2012). Demand response in electricity markets: A review. In European Energy market (EEM), 2012 9th international conference on the. IEEE (pp. 1-8).

45. Fadlullah, Z. M., Quan, D. M., Kato, N., et al. (2014). GTES: An optimized game-theoretic demand-side management scheme for smart grid. IEEE Systems Journal, 8(2), 588-597.

46. Wu, H., Shahidehpour, M., \& Khodayar, M. E. (2013). Hourly demand response in day-ahead scheduling considering generating unit ramping cost. IEEE Transactions on Power Systems, 28(3), 2446-2454.
47. Shao, S., Pipattanasomporn, M., \& Rahman, S. (2013). Development of physical-based demand response-enabled residential load models. IEEE Transactions on Power Systems, 28(2), 607-614.

48. Sheikhi, A., Rayati, M., Bahrami, S., et al. (2015). Integrated demand side management game in smart energy hubs. IEEE Transactions on Smart Grid, 6(2), 675-683.

49. Bahrami, S., \& Sheikhi, A. (2016). From demand response in smart grid toward integrated demand response in smart Energy hub. IEEE Transactions on Smart Grid, 7(2), 650-658.

50. Arteconi, A., Patteeuw, D., Bruninx, K., et al. (2016). Active demand response with electric heating systems: Impact of market penetration. Applied energy, $177,636-648$.

51. Patteeuw, D., Reynders, G., Bruninx, K., et al. (2015). CO2-abatement cost of residential heat pumps with active demand response: Demand-and supplyside effects. Applied Energy, 156, 490-501.

52. Ali, M., Jokisalo, J., Siren, K., et al. (2014). Combining the demand response of direct electric space heating and partial thermal storage using LP optimization. Electric Power Systems Research, 106, 160-167.

53. Alimohammadisagvand, B., Jokisalo, J., Kilpeläinen, S., et al. (2016). Costoptimal thermal energy storage system for a residential building with heat pump heating and demand response control. Applied Energy, 174, 275-287.

54. Schibuola, L., Scarpa, M., \& Tambani, C. (2015). Demand response management by means of heat pumps controlled via real time pricing. Energy and Buildings, 90, 15-28.

55. Wang, H., Meng, K., Luo, F., et al. (2013). Demand response through smart home energy management using thermal inertia. In Power engineering conference (AUPEC), 2013 Australasian universities (pp. 1-6). Hobart: IEEE.

56. Arteconi, A., Hewitt, N. J., \& Polonara, F. (2013). Domestic demand-side management (DSM): Role of heat pumps and thermal energy storage (TES) systems. Applied thermal engineering, 51(1-2), 155-165.

57. Zhang, L., Good, N., Navarro-Espinosa, A., et al. (2014). Modelling of household electro-thermal technologies for demand response applications. In Innovative smart grid technologies conference Europe (ISGT-Europe), 2014 IEEE PES (pp. 1-6). Istanbul: IEEE.

58. Wang, D., Parkinson, S., Miao, W., et al. (2012). Online voltage security assessment considering comfort-constrained demand response control of distributed heat pump systems. Applied Energy, 96, 104-114.

59. Houwing, M., Negenborn, R. R., \& De Schutter, B. (2011). Demand response with micro-CHP systems. Proceedings of the IEEE, 99(1), 200-213.

60. Nian, L. I. U., Jie, W., \& Lingfeng, W. (2017). Distributed energy management for interconnected operation of combined heat and power-based microgrids with demand response. Journal of Modern Power Systems and Clean Energy, 5(3), 478-488.

61. Patteeuw, D., Bruninx, K., Arteconi, A., et al. (2015). Integrated modeling of active demand response with electric heating systems coupled to therma energy storage systems. Applied Energy, 151, 306-319.

62. Aghaei, J., \& Alizadeh, M. I. (2013). Multi-objective self-scheduling of CHP (combined heat and power)-based microgrids considering demand response programs and ESSs (energy storage systems). Energy, 55, 1044-1054.

63. Neves, D., \& Silva, C. A. (2015). Optimal electricity dispatch on isolated minigrids using a demand response strategy for thermal storage backup with genetic algorithms. Energy, 82, 436-445.

64. Baeten, B., Rogiers, F., \& Helsen, L. (2017). Reduction of heat pump induced peak electricity use and required generation capacity through thermal energy storage and demand response. Applied Energy, 195, 184-195.

65. Alipour, M., Zare, K., \& Mohammadi-Ivatloo, B. (2014). Short-term scheduling of combined heat and power generation units in the presence of demand response programs. Energy, 71, 289-301.

66. Alipour, M., Mohammadi-lvatloo, B., \& Zare, K. (2014). Stochastic riskconstrained short-term scheduling of industrial cogeneration systems in the presence of demand response programs. Applied Energy, 136, 393-404.

67. Gitizadeh, M., Farhadi, S., \& Safarloo, S. (2014). Multi-objective energy management of CHP-based microgrid considering demand response programs. In Smart grid conference (SGC), 2014 (pp. 1-7). Tehran: IEEE.

68. Arteconi, A., Hewitt, N. J., \& Polonara, F. (2012). State of the art of thermal storage for demand-side management. Applied Energy, 93, 371-389.

69. Cui, H., Li, F., Hu, Q., et al. (2016). Day-ahead coordinated operation of utilityscale electricity and natural gas networks considering demand response based virtual power plants. Applied energy, 176, 183-195.

70. Zhang, X., Che, L., Shahidehpour, M., et al. (2016). Electricity-natural gas operation planning with hourly demand response for deployment of flexible ramp. IEEE Transactions on Sustainable Energy, 7(3), 996-1004. 
71. Zhang, X., Shahidehpour, M., Alabdulwahab, A., et al. (2016). Hourly electricity demand response in the stochastic day-ahead scheduling of coordinated electricity and natural gas networks. IEEE Transactions on Power Systems, 31(1), 592-601.

72. Bai, L., Li, F., Cui, H., et al. (2016). Interval optimization based operating strategy for gas-electricity integrated energy systems considering demand response and wind uncertainty. Applied energy, 167, 270-279.

73. Sheikhi, A., Rayati, M., \& Ranjbar, A. M. (2016). Demand side management for a residential customer in multi-energy systems. Sustainable Cities and Society, 22, 63-77.

74. Jabari, F., Nojavan, S., Ivatloo, B. M., et al. (2016). Optimal short-term scheduling of a novel tri-generation system in the presence of demand response programs and battery storage system. Energy Conversion and Management, 122, 95-108.

75. Majidi, M., Nojavan, S., \& Zare, K. (2017). Optimal stochastic short-term thermal and electrical operation of fuel cell/photovoltaic/battery/grid hybrid energy system in the presence of demand response program. Energy Conversion and Management, 144, 132-142.

76. Nguyen, D. T., \& Le, L. B. (2014). Optimal bidding strategy for microgrids considering renewable energy and building thermal dynamics. IEEE Transactions on Smart Grid, 5(4), 1608-1620.

77. Wang, J., Zhong, H., Xia, Q., et al. (2017). Optimal joint-dispatch of energy and reserve for CCHP-based microgrids. IET Generation, Transmission \& Distribution, 11(3), 785-794.

78. Geidl, M. (2007). Integrated modeling and optimization of multi-carrier energy system. Zurich: ETH Zurich.

79. Neyestani, N., Damavandi, M. Y., Shafie-Khah, M., et al. (2015). Uncertainty characterization of carrier-based demand response in smart multi-energy systems. In 2015 IEEE 5th international conference on power engineering, Energy and electrical drives (POWERENG) (pp. 366-371). Riga: IEEE.

80. Majidi, M., Nojavan, S., \& Zare, K. (2017). A cost-emission framework for hub energy system under demand response program. Energy, 134, 157-166.

81. Batić, M., Tomašević, N., Beccuti, G., et al. (2016). Combined energy hub optimisation and demand side management for buildings. Energy and Buildings, 127, 229-241.

82. Pazouki, S., \& Haghifam, M. R. (2014). Comparison between demand response programs in multiple carrier energy infrastructures in presence of wind and energy storage technologies. In Smart grid conference (SGC), 2014 (pp. 1-6). Tehran: IEEE.

83. Alipour, M., Zare, K., \& Abapour, M. (2018). MINLP probabilistic scheduling model for demand response programs integrated energy hubs. IEEE Transactions on Industrial Informatics, 14(1), 79-88.

84. Brahman, F., Honarmand, M., \& Jadid, S. (2015). Optimal electrical and thermal energy management of a residential energy hub, integrating demand response and energy storage system. Energy and Buildings, 90, 65-75.

85. Pazouki, S., \& Haghifam, M. R. (2016). Optimal planning and scheduling of energy hub in presence of wind, storage and demand response under uncertainty. International Journal of Electrical Power \& Energy Systems, 80, 219-239.

86. Ahčin, P., \& Šikić, M. (2010). Simulating demand response and energy storage in energy distribution systems. In Power system technology (POWERCON), 2010 international conference on. IEEE (pp. 1-7).

87. Vahid-Pakdel, M. J., Nojavan, S., Mohammadi-lvatloo, B., et al. (2017). Stochastic optimization of energy hub operation with consideration of thermal energy market and demand response. Energy Conversion and Management, 145, 117-128.

88. Dolatabadi, A., \& Mohammadi-Ivatloo, B. (2017). Stochastic risk-constrained scheduling of smart energy hub in the presence of wind power and demand response. Applied Thermal Engineering, 123, 40-49.

89. Pazouki, S., Haghifam, M. R., \& Moser, A. (2014). Uncertainty modeling in optimal operation of energy hub in presence of wind, storage and demand response. International Journal of Electrical Power \& Energy Systems, 61, 335-345.

90. Kienzle, F., Ahcin, P., \& Andersson, G. (2011). Valuing investments in multienergy conversion, storage, and demand-side management systems under uncertainty. IEEE Transactions on Sustainable Energy, 2(2), 194-202.

91. Pazouki, S., Haghifam, M. R., \& Olamaei, J. (2013). Economical scheduling of multi carrier energy systems integrating renewable, energy storage and demand response under energy hub approach. In Smart grid conference (SGC), 2013 (pp. 80-84). Tehran: IEEE.

92. Sheikhi, A., Rayati, M., Bahrami, S., et al. (2015). A cloud computing framework on demand side management game in smart energy hubs. International Journal of Electrical Power \& Energy Systems, 64, 1007-1016.
93. Sheikhi, A., Bahrami, S., \& Ranjbar, A. M. (2015). An autonomous demand response program for electricity and natural gas networks in smart energy hubs. Energy, 89, 490-499.

94. Yang, H., Xiong, T., Qiu, J., et al. (2016). Optimal operation of DES/CCHP based regional multi-energy prosumer with demand response. Applied Energy, 167, 353-365.

95. DOE of United States. Grid 2030: A national vision for electricity's second 100 years [EB/OL]. [2016-12-10].https://www.ferc.gov/eventcalendar/Files/ 20050608125055-grid-2030.pdf.

96. Huang, A. (2010). FREEDM system-a vision for the future grid, Power and Energy society general meeting, 2010 IEEE (pp. 1-4). Providence: IEEE.

97. Huang, A. Q., Crow, M. L., Heydt, G. T., et al. (2011). The future renewable electric Energy delivery and management (FREEDM) system: The Energy internet. Proceedings of the IEEE, 99(1), 133-148.

98. Vermesan, O., Blystad, L. C., Zafalon, R., et al. (2011). Internet of Energyconnecting Energy anywhere anytime. In Advanced microsystems for automotive applications 2011 (pp. 33-48). Berlin, Heidelberg: Springer.

99. Qadrdan, M., Chaudry, M., Wu, J., et al. (2010). Impact of a large penetration of wind generation on the GB gas network. Energy Policy, 38(10), 5684-5695.

100. CATAPULT.Energy Systems Catapult [EB/OL]. [2016-12-10]. https://es.catapult. org.uk/.

101. Geidl, M, Andersson G. (2005). A modeling and optimization approach for multiple energy carrier power flow[C]//2005 IEEE Russia Power Tech (1-7). St. Petersburg: IEEE.

102. Geidl, M., Koeppel, G., Favre-Perrod, P., et al. (2007). Energy hubs for the future. IEEE Power and Energy Magazine, 5(1), 24-30.

103. Geidl, M., \& Andersson, G. (2007). Optimal power flow of multiple energy carriers [J]. IEEE Transactions on Power Systems, 22(1), 145-155.

104. The State Council (2015) Guidelines of the state council on actively pushing "internet+" action. Available via DIALOG. http://www.gov.cn/zhengce/ content/2015-07/04/content_10002.htm. Accessed 9 June 2016.

\section{Submit your manuscript to a SpringerOpen ${ }^{\circ}$ journal and benefit from:}

- Convenient online submission

- Rigorous peer review

- Open access: articles freely available online

- High visibility within the field

- Retaining the copyright to your article

Submit your next manuscript at $>$ springeropen.com 